\title{
Theory of Plastic Mechanism Control of Seismic-Resistant MR-Frames with Set-Backs
}

\author{
R. Montuori, M. Troisi and V. Piluso*
}

\author{
Department of Civil Engineering, University of Salerno, Fisciano, Italy
}

\begin{abstract}
Seismic codes do not provide specific hierarchy criteria for irregular Moment Resisting Frames (MRFs). In fact, the provisions for irregular frames are exactly the same adopted for regular MRFs with the only exception of a $20 \%$ reduction of the design value of the q-factor, accounting for a presumed worsening of the frame energy dissipation capacity.

It is well known that seismic code provisions, based on hierarchy criteria, are often unsuitable to prevent partial mechanisms and to assure the development of a global collapse mechanism. In particular, irregular structures are prone to develop partial or soft storey mechanisms in case of significant set-backs. As already showed in previous work [1-10] a rational design procedure based on plastic mechanism theory can be adopted for different design typologies leading to excellent results in the field of mechanism control. This procedure is herein briefly presented and applied to different study cases. It is based on the application of the kinematic theorem of plastic collapse extended to the concept of mechanism equilibrium curve in order to consider second order effects. Sending the reader back to the original work on the theory of plastic mechanism control [1] for an exhaustive presentation of the theory, referred to regular MR-Frames, the work herein presented focuses on the issues to be faced to apply such theory to the particular case of steel frames with setbacks. In order to verify the results obtained by the application of the proposed design procedure, non linear static analyses [11] have been carried out for all the structures considered and a comparison with the results coming from the application of Eurocode 8 design procedures [12] is also performed.
\end{abstract}

Keywords: Moment resisting frames, global mechanism, mechanism equilibrium curve, design methodology, non linear static analyses.

\section{INTRODUCTION}

It is universally recognized that failure mode control is a fundamental requirement for designing seismic resistant structures, because local failure modes, such as partial and soft-storey mechanisms, lead to damage concentration and, as a consequence, to the premature collapse of structures. For this reason, the development of a collapse mechanism of global type [1-10] is promoted by modern seismic codes by means of simplified design rules. The first studies on this topic have been carried out mainly with reference to reinforced concrete frames and, in particular, in New Zealand where the capacity design procedure has been in use since 1980 [13-15]. Nowadays, with reference to new buildings, the need to control the location of dissipative zones is recognized to be of primary importance independently of the constructional material [12-19]. Similarly, in the case of existing reinforced concrete buildings the seismic retrofitting interventions can be focused on some properly selected structural elements whose strengthening [20] is aimed at the modification of the pattern of yielding to prevent, at least, the most severe and undesired failure modes.

Regarding new buildings, the first step in the seismic design of dissipative structures is the selection of a suitable

* Address correspondence to this author at the Vincenzo Piluso University of Salerno, Via Ponte Don Melillo, 84084 Fisciano (Sa), Italy;

Tel. +39089 964108; Fax: +39+089968731; E-mail: v.piluso@unisa.it location of dissipative zones, i.e. a suitable collapse mecha nism. Non-dissipative parts of dissipative seismic resistant structures and their connections to the dissipative ones have to be designed with sufficient overstrength to allow the cyclic yielding of the dissipative parts. This means that nondissipative parts have to be designed in order to remain in the elastic range and, therefore, they have to be proportioned on the basis of the maximum internal actions that the dissipative zones are able to transmit. Conversely, the dissipative zones have to be proportioned on the basis of internal actions arising from the seismic forces prescribed by the codes. This is the general criterion for designing seismic-resistant dissipative structures and represents the so-called "capacity design approach". This definition means that non-dissipative parts have to be designed for the "capacity" of the fully yielded and strain-hardened dissipative zones [16]. More recently the capacity design approach has been recognized as a powerful tool to design also beam-to-column connections by means of the component method [18], so that hierarchy criteria at the joint component level can be properly identified.

In the case of moment resisting frames, the design criterion suggested by seismic codes is the adoption of columns having a flexural resistance greater than that of the connected beams. However, the fulfillment of this design criterion, namely member hierarchy criterion, is able to prevent the development of storey mechanisms only, but it is not sufficient to guarantee the formation of a collapse mechanism of 

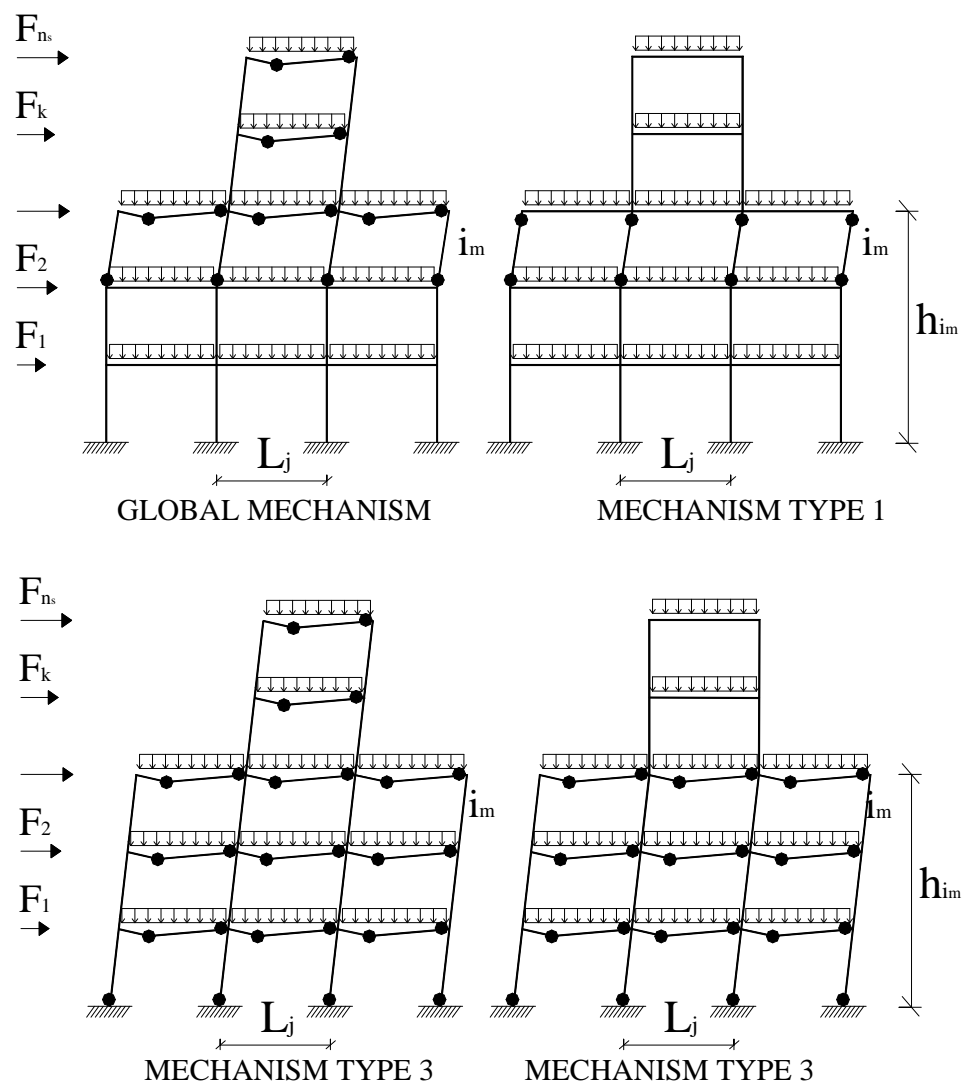

Fig. (1). Collapse mechanism typologies.

global type. In fact, as demonstrated by numerous numerical studies dealing with the seismic inelastic performances of steel frames, this ambitious pattern of yielding cannot be realized by means of simplified design rules. Moreover, it is easy to realize and verify that in case of irregular moment resisting frames the development of a global type mechanism is even more complicated to obtain than in case of regular frames. In fact, due to the presence of geometrical irregularities, big variations of masses and lateral stiffnesses along the building height can easily arise and, as a consequence, soft storey mechanisms are more prone to develop.

The innovative design methodology, presented in this paper with reference to irregular moment resisting frames, is based on the kinematic theorem of plastic collapse. According to such theorem, the kinematically admissible multiplier of horizontal forces associated to the failure mode is the minimum among the kinematically admissible multipliers associated to all the collapse mechanisms. Therefore, in order to control the failure mode, i.e to obtain a collapse mechanism characterised by plastic hinge formation at all the beam ends and at the base of the first storey columns, it has to be imposed that the kinematically admissible multiplier corresponding to the global mechanism has to be less than those corresponding to all the undesired partial mechanisms. In this paper, the attention is focused on the additional design issues to be considered in case of irregular MR-Frames with set-backs and the results coming out by several non linear static analyses are presented showing that the global collapse mechanism, i.e. the plasticization of all the beam ends and of the column base sections, can be really achieved by applying the proposed design methodology.

\section{PROPOSED DESIGN PROCEDURE}

The innovative design methodology, briefly summarized in this paper with reference to irregular moment resisting frames with set-backs, is based on the kinematic theorem of plastic collapse. According to such theorem, the kinematically admissible multiplier of horizontal forces associated to the failure mode is the minimum among the kinematically admissible multipliers associated to all the collapse mechanisms. Therefore, in order to control the failure mode, i.e to obtain a collapse mechanism characterized by plastic hinge formation at all the beam ends and at the base of the first storey columns, it has to be imposed that the kinematically admissible multiplier corresponding to the global mechanism has to be less than those corresponding to all the undesired partial mechanisms.

In particular, collapse mechanisms can be considered as belonging to three main typologies, as depicted in Fig. (1) with reference to failure modes whose mechanism index corresponds to the $\mathrm{i}_{\mathrm{m}}$ th storey (the global mechanism can be regarded as a particular case of type- 2 mechanism where all the storeys are involved).

Therefore, $3 \mathrm{~ns}$ design conditions can be obtained, where $\mathrm{ns}$ is the number of storeys. By dimensioning the beam sections to resist vertical loads, the design conditions allow to design the column sections, constituting the only unknowns of the design process. 
Nevertheless, such approach is able to assure the development of the desired mechanism provided that the structural material behaves as rigid-plastic. Conversely, the actual behavior is elasto-plastic so that structures exhibit significant lateral displacements before failure, and second order effects cannot be neglected in the design procedure. To this scope, a linearised mechanism equilibrium curve can be used to represent the structural behavior $[1,7]$ :

$\alpha_{\mathrm{c}}=\alpha-\gamma \cdot \delta$

where $\alpha$ and $\gamma$ are, respectively, the kinematically admissible multiplier of horizontal forces and the slope of the mechanism equilibrium curve, obtained by means of the virtual work principle. For a virtual rotation $d \theta$ of the columns involved in the mechanism, the internal and the external work can be expressed, respectively, as:

$$
\begin{aligned}
& W_{i}=\left[\operatorname{tr}\left(\mathbf{C}^{\mathrm{T}} \mathbf{R}_{\mathbf{c}}\right)+2 \operatorname{tr}\left(\mathbf{B}^{\mathrm{T}} \mathbf{R}_{\mathbf{b}}\right)\right] \mathrm{d} \theta \\
& W_{e}=\left[\alpha_{\mathrm{c}} \cdot \mathbf{F}^{\mathrm{T}} \mathbf{S}+\operatorname{tr}\left(\mathbf{q}^{\mathrm{T}} \mathbf{D}_{\mathbf{v}}\right)+\mathbf{V}^{\mathrm{T}} \mathbf{s} \cdot \frac{\delta}{H_{0}}\right] \mathrm{d} \theta
\end{aligned}
$$

where:

tr denotes the trace of the matrix;

- $\mathbf{C}$ is a matrix of order $n_{c} \times n_{s}$ (number of columns $\times$ number of storeys) whose elements $C_{i k}$ are equal to the plastic moments of columns $\left(C_{i k}=M_{c, i k}\right)$;

- $\quad \mathbf{R}_{\mathbf{c}}$ is a matrix of order $n_{c} \times n_{s}$ whose elements, $R_{c, i k}$, are coefficients accounting for the participation of ith column of kth storey to the collapse mechanism. In particular $R_{c, i k}=2$ when the column is yielded at both ends, $R_{c, i k}$ $=1$ when only one column end is yielded, and $R_{c, i k}=0$ when the column does not participate to the collapse mechanism;

- $\mathbf{B}$ is a matrix of order $n_{b} \times n_{s}$ (number of bays $\times$ number of storeys) whose elements $B_{j k}$ are equal to plastic moments of beams $\left(B_{j k}=M_{b, j k}\right)$;

- $\quad \mathbf{R}_{\mathbf{b}}$ is a matrix of order $n_{b} \times n_{s}$ whose elements, $R_{b, j k}$, are coefficients accounting for the participation of $\mathrm{j}$ th beam of $\mathrm{k} t h$ storey to the collapse mechanism. In particular $R_{b, j k}=0$ when the beam does not participate to the collapse, otherwise $R_{b, j k}=L_{j} /\left(L_{j}-x_{j k}\right)$, where $L_{j}$ is the span of $\mathrm{j} t h$ bay and $x_{j k}$ is the abscissa of second plastic hinge of $\mathrm{j}$ th beam of $\mathrm{k} t h$ storey. This abscissa is given by $x_{j k}=L_{j}-2\left(M_{b, j k} / q_{j k}\right)^{1 / 2}$ when the uniform vertical load $q_{j k}>4 \cdot M_{b, j k} / L_{j}^{2}$ and by $x_{j k}=0$ in the opposite case [1];

- $\mathbf{F}^{\mathbf{T}}$ is the vector of the design seismic horizontal forces equal to $\left\{F_{1}, F_{2}, \ldots \ldots, F_{k}, \ldots \ldots, F_{n s}\right\}$, where $F_{k}$ is the horizontal force applied to the kth storey;

- $\mathbf{s}$ is the shape vector of the storey horizontal virtual displacements $(\mathrm{d} \mathbf{u}=\mathbf{s} \cdot d \theta$, where $d \theta$ is the virtual rotation of the plastic hinges of the columns involved in the mechanism);

- $\mathbf{q}$ is the matrix of order $n_{b} \times n_{s}$ (number of bays $\times$ number of storeys) of uniform vertical loads acting on the beams;
- $\mathbf{D}_{\mathbf{v}}$ is a matrix of order $n_{b} \times n_{s}$ whose elements, $D_{v, j k}$, are coefficients related to the external work of the uniform load acting on jth beam of $\mathrm{k} t h$ storey. In particular $D_{v, j k}$ $=L_{j} x_{j k} / 2$ when the beam participates to the collapse mechanism and $D_{v, j k}=0$ in the opposite case;

- $\mathbf{V}$ is the vector of the storey vertical loads $\left\{V_{l}, V_{2}, \ldots\right.$, $\left.V_{k}, \ldots, V_{n s}\right\}$, where $V_{k}$ is the total load acting at kth storey;

- $\mathbf{s} \delta / H_{0}$ is the shape vector of the storey vertical virtual displacements, being $\mathbf{s}$ the shape vector of the storey horizontal virtual displacements, $\delta$ the top sway displacement of the structure and $H_{0}$ the sum of the interstorey heights of all the storeys involved in the kinematic mechanism.

The application of the virtual work principle provides the following expression for the lateral force multiplier:

$\alpha_{\mathrm{c}}=\frac{\left[\operatorname{tr}\left(\mathbf{C}^{\mathrm{T}} \mathbf{R}_{\mathbf{c}}\right)+2 \operatorname{tr}\left(\mathbf{B}^{\mathrm{T}} \mathbf{R}_{\mathbf{b}}\right)-\operatorname{tr}\left(\mathbf{q}^{\mathrm{T}} \mathbf{D}_{\mathbf{v}}\right)\right]}{\mathbf{F}^{\mathrm{T}} \mathbf{s}}-\left(\frac{\mathbf{V}^{\mathrm{T}} \mathbf{s}}{\mathbf{F}^{\mathrm{T}} \mathbf{s}} \cdot \frac{1}{H_{0}}\right) \cdot \delta$

By comparing Eqs. (1) and, (4) the expression of the kinematically admissible multiplier of horizontal forces $\alpha$ and the slope of the mechanism equilibrium curve $\gamma$ can be obtained:

$\alpha=\frac{\operatorname{tr}\left(\mathbf{C}^{\mathrm{T}} \mathbf{R}_{\mathbf{c}}\right)+2 \operatorname{tr}\left(\mathbf{B}^{\mathrm{T}} \mathbf{R}_{\mathbf{b}}\right)-\operatorname{tr}\left(\mathbf{q}^{\mathrm{T}} \mathbf{D}_{\mathbf{v}}\right)}{\mathbf{F}^{\mathrm{T}} \mathbf{S}}$

$\tilde{\mathbf{a}}=\frac{\mathbf{V}^{\mathbf{T}} \mathbf{s}}{\mathbf{F}^{\mathbf{T}} \mathbf{s}} \cdot \frac{1}{H_{0}}$

From Eqs. (5) and (6), $\alpha_{i_{m}}{ }^{(t)}$ and $\gamma_{i_{m}}{ }^{(t)}$, i.e. the kinematically admissible multiplier and the slope of the equilibrium curve corresponding to the mechanism of type- $t$ with mechanism index $\mathrm{i}_{\mathrm{m}}$, can be derived by properly quantifying the contribution of columns, the participation of beams $\left(\mathbf{R}_{\mathbf{b}}\right)$, the external work of uniform loads $\left(\mathbf{D}_{\mathbf{v}}\right)$ and the shape vector of horizontal virtual displacements (s). As an example, with reference to the $i_{\mathrm{m}}$ th mechanism of type-2, plastic hinges develop at the base of $\mathrm{i}_{\mathrm{m}}$ th storey columns, whereas only beams up to the $\mathrm{i}_{\mathrm{m}}$ th storey are involved, so that Eqs. (5) and (6) give:

$\alpha_{\mathrm{i}_{\mathrm{m}}}{ }^{(2)}=\frac{\mathbf{M}_{\mathbf{c}, \mathbf{i}_{\mathrm{m}}}^{\mathbf{T}} \mathbf{I}+2 \operatorname{tr}\left(\mathbf{B}^{\mathrm{T}} \mathbf{R}_{\mathrm{b}, \mathbf{i}_{\mathrm{m}}}^{(2)}\right)-\operatorname{tr}\left(\mathbf{q}^{\mathrm{T}} \mathbf{D}_{\mathrm{v}, \mathbf{i}_{\mathrm{m}}}^{(2)}\right)}{\mathbf{F}^{\mathrm{T}} \mathbf{s}_{\mathbf{i}_{\mathrm{m}}}^{(2)}}$

$\gamma_{\mathrm{i}_{\mathrm{m}}}{ }^{(2)}=\frac{\mathbf{V}^{\mathbf{T}} \mathbf{s}_{\mathbf{i}_{\mathrm{m}}}^{(2)}}{\mathbf{F}^{\mathbf{T}} \mathbf{s}_{\mathbf{i}_{\mathrm{m}}}^{(2)}} \cdot \frac{1}{h_{n s}-h_{i_{m}-1}}$

where $\mathbf{M}_{\mathbf{c}, \mathbf{i}_{\mathrm{m}}}$ is the vector of $\mathbf{i}_{\mathrm{m}}$ th storey column plastic moments accounting for the bending moment - axial force interaction, $H_{0}=h_{n s^{-}} h_{i m-1}$ and $\mathbf{s}_{\mathbf{i m}}{ }^{(\mathbf{})}=\left\{0,0, \ldots, h_{i m}-h_{i m-1}, h_{i m+1^{-}}\right.$ $\left.h_{i m-1}, \ldots, h_{n s}-h_{i m-1}\right\}^{\mathrm{T}}$, being the first component different from zero the $\mathrm{i}_{\mathrm{m}}$ th one. Similarly, the kinematically admissible multiplier and the slope of the equilibrium curve can be derived with reference to the other mechanism typologies.

By introducing second order effects in the design procedure, the application of the upper bound theorem, aimed at 
promoting a global collapse mechanism, consists in imposing that the equilibrium curve corresponding to the global mechanism has to lie below the mechanism equilibrium curves corresponding to all the other undesired partial mechanisms. Such condition has to be satisfied up to a given displacement level, $\delta_{u}$, so that the design conditions can be expressed by means of the following relationships [1]:

$\alpha^{(g)}-\gamma^{(g)} \cdot \delta_{u} \leq \alpha_{i_{m}}{ }^{(t)}-\gamma_{i_{m}}{ }^{(t)} \cdot \delta_{u}$

with $i_{m}=1,2,3, \ldots, n_{s}$ and $t=1,2,3$. Regarding the ultimate displacement, it has to be adequately chosen according to local ductility supply.

By properly solving the $3 n_{s}$ design conditions provided by Eq. (9) [1,7], the sum of column plastic moments, reduced due to the contemporary action of axial forces, required to prevent the development of undesired collapse mechanisms is obtained for each storey. The final step consists in distributing such sum among the storey columns. In case of regular MRFs [1] and dual systems CBF-MRFs [7] column sections can be dimensioned by simply distributing the required sum of column plastic moments among the storey columns proportionally to the axial forces occurring at collapse. This way of distributing the required sum of column plastic moments has been denoted in the following as case "A0". In case of irregular moment resisting frames with set-backs, as an alternative to this criterion, a more rational choice accounting for the geometrical characteristics of the structural scheme can be made. This alternative choice consists in the preliminary design of columns corresponding to set-backs by simply applying the hierarchy criterion to address plastic hinge formation in beams rather than in columns. In case of only one bay set-back, the external column can be dimensioned by imposing that its plastic moment has to be not less than the one of the adjacent beam (as an example column 51 or column 42 in Fig. (2). In case of two or more than two bay set-backs, the internal columns belonging to the zone affected by set-backs can be dimensioned by assuming that the plastic moment has to be not less than the sum of the plastic moments of the adjacent beams (as an example column 32 in Fig. (2). As a consequence, the remaining storey columns can be dimensioned by distributing the residual required sum of storey column plastic moments (required sum of storey column plastic moments minus the plastic moments of the columns already designed) proportionally to the axial forces occurring in such columns in the collapse condition. Such column axial forces can be easily evaluated accounting for the shear forces transmitted by the beams in the global mechanism configuration [1]. Such alternative criterion of distributing the required sum of column plastic moments at each storey has been herein denoted as case "A1".

It has to be underlined that, according to actual code provisions [12-17] hierarchy criterion does not apply to top storey columns. In such case column sections can be dimensioned by simply distributing the required sum of column plastic moments among the top storey columns proportionally to the axial forces occurring at collapse.

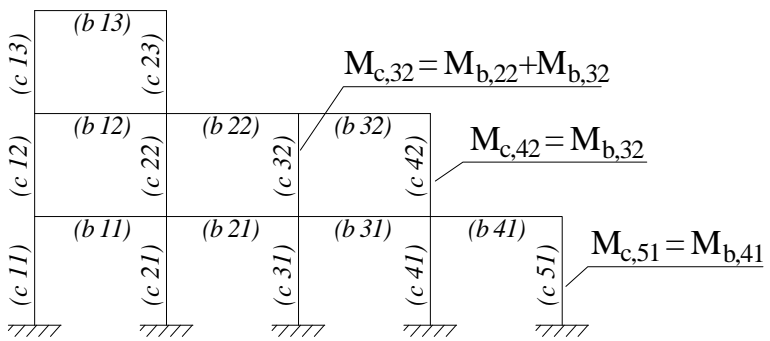

Fig. (2). Criterion A1 for designing columns of set-backs. (beam and column labels in round brackets).

\section{NON LINEAR STATIC ANALYSES}

In order to evaluate the accuracy of the proposed design methodology, an adequate number of irregular MRFs having different numbers of storeys and different structural configuration have been designed.

The considered geometrical configurations are depicted in Fig. (3). The span length and the interstorey height are equal to $5.0 \mathrm{~m}$ and $3.5 \mathrm{~m}$, respectively. The values of dead $\left(G_{k}\right)$ and live $\left(Q_{k}\right)$ loads are, respectively, equal to $15 \mathrm{kN} / \mathrm{m}$ and $10 \mathrm{kN} / \mathrm{m}$. The steel grade is $\mathrm{S} 275$.

The seismic horizontal forces Fig. (3) have been determined according to Eurocode 8 [12], assuming a peak ground acceleration equal to $0.35 \mathrm{~g}$, a seismic response amplification factor equal to 2.5, soil type A-1 and behavior factor $q$ equal to 5.2, which is obtained accounting for irregularity along the height. In fact, for an irregular MRF the $q$ factor is obtained by reducing the value of regular MRFs $q$ factor by means of a coefficient equal to 0.8 , so it is:

$q=0.8 \cdot 5 \cdot \frac{\alpha_{u}}{\alpha_{y}}=0.8 \cdot 5 \cdot 1.3=5.2$

As described above, the beams have to be designed to resist to vertical load, so the plastic moment of the beam can be chosen in the range $Q L^{2} / 8-Q L^{2} / 12$ being $Q$ the vertical load acting in the vertical load combination $\left(1.35 \mathrm{~g}_{\mathrm{k}}+1.5 \mathrm{q}_{\mathrm{k}}\right)$ and $L$ the spam length. Concerning the case herein consid-
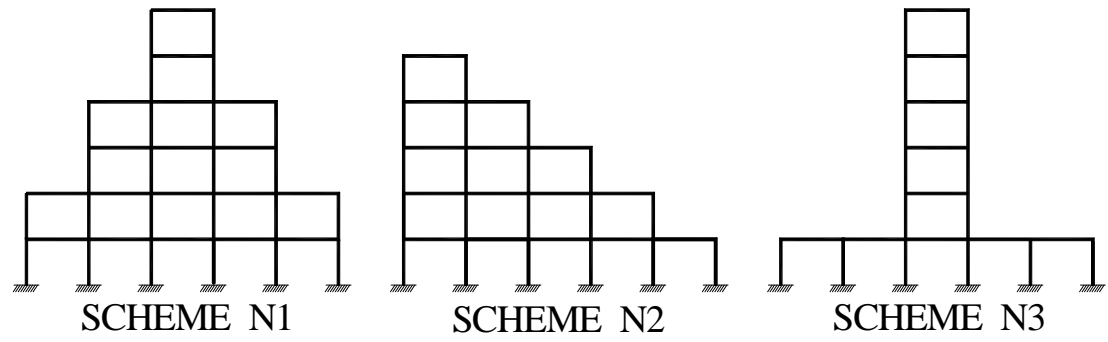

Figure (3). Analyzed Structural schemes.

Fig. (3). Analyzed Structural schemes. 
Table 1. Column sections for structure N1.

\begin{tabular}{|c|c|c|c|c|}
\hline STOREY & BAY & $\begin{array}{c}\text { CRITERION } \\
\text { A0 }\end{array}$ & $\begin{array}{c}\text { CRITERION } \\
\text { A1 }\end{array}$ & EC8 \\
\hline \multirow{2}{*}{6} & 3 & HEB 200 & HEB 200 & HEB 160 \\
\hline & 4 & HEB 200 & HEB 200 & HEB 160 \\
\hline 5 & 3 & HEB 220 & HEB 220 & HEB 220 \\
\hline \multirow{4}{*}{4} & 2 & HEB 180 & HEB 200 & HEB 160 \\
\hline & 3 & HEB 260 & HEB 240 & HEB 220 \\
\hline & 4 & HEB 260 & HEB 240 & HEB 220 \\
\hline & 5 & HEB 180 & HEB 200 & HEB 160 \\
\hline 3 & 5 & HEB 220 & HEB 220 & HEB 220 \\
\hline \multirow{6}{*}{2} & 1 & HEB 160 & HEB 200 & HEB 180 \\
\hline & 2 & HEB 240 & HEB 240 & HEB 220 \\
\hline & 3 & HEB 300 & HEB 280 & HEB 240 \\
\hline & 4 & HEB 300 & HEB 280 & HEB 240 \\
\hline & 5 & HEB 240 & HEB 240 & HEB 220 \\
\hline & 6 & HEB 160 & HEB 200 & HEB 180 \\
\hline 1 & 6 & HEB 220 & HEB 220 & HEB 180 \\
\hline
\end{tabular}

ered, an IPE240 has a plastic moment corresponding to the value of $Q L^{2} / 10.8$. Once the beam has been chosen the proposed design procedure can be applied and column sections can be determined.

The design value of the ultimate displacement has been related to the local ductility supply by assuming $\delta_{u}=\theta_{p} \mathrm{H}$, where $\theta_{p}$ is the plastic rotation supply of beams and columns of first storey, assumed equal to $0.04 \mathrm{rad}$, and $H$ is the height of the structure.

It is important to underline that also the checks against serviceability limit state requirements need to be carried out. In fact, it is not assured that a structure designed for failure mode control is also able to exhibit adequate lateral stiffness to satisfy interstorey drift limitations provided by actual seismic codes.

In such a case, in order to design structures both failing in global mode and satisfying code requirements dealing with the serviceability limit state, the proposed design pro- cedure has to be repeated by increasing the beam sections or the design ultimate displacement until the interstorey drift limitation is satisfied [7]. In the case herein analyzed, for structural scheme $\mathrm{N} 1$, in order to satisfy also serviceability requirements, the beam section has been increased from IPE240, i.e. the original selection accounting for the beam vertical loads only, to IPE270 standard shape. By repeating the design procedure with the corresponding new value of the beam plastic resistance, a new set of column sections is obtained. The obtained structure Table 1 satisfies both mechanism control requirements and serviceability limit state requirements.

Also regarding structures designed according to EC8 provisions, the same criterion has been adopted. In this case an IPE300 needs to be adopted in order to satisfy the serviceability limit state requirements. The columns obtained according to the proposed design procedure, with reference to the two alternative criteria for distributing the sum of column plastic moments needed to assure the global failure 
Table 2. Column sections for structure N2.

\begin{tabular}{|c|c|c|c|c|}
\hline STOREY & BAY & $\begin{array}{c}\text { CRITERION } \\
\text { A0 }\end{array}$ & $\begin{array}{c}\text { CRITERION } \\
\text { A1 }\end{array}$ & EC8 \\
\hline 5 & 1 & HEB 200 & HEB 200 & HEB 160 \\
\hline \multirow[b]{2}{*}{4} & 1 & HEB 240 & HEB 240 & HEB 160 \\
\hline & 2 & HEB 240 & HEB 220 & HEB 200 \\
\hline \multirow{4}{*}{3} & 1 & HEB 260 & HEB 240 & HEB 160 \\
\hline & 2 & HEB 260 & HEB 240 & HEB 220 \\
\hline & 3 & HEB 220 & HEB 200 & HEB 200 \\
\hline & 4 & HEB 180 & HEB 200 & HEB 200 \\
\hline \multirow{2}{*}{2} & 1 & HEB 260 & HEB 280 & HEB 160 \\
\hline & 5 & HEB 160 & HEB 200 & HEB 200 \\
\hline \multirow{6}{*}{1} & 1 & HEB 300 & HEB 300 & HEB 160 \\
\hline & 2 & HEB 280 & HEB 300 & HEB 220 \\
\hline & 3 & HEB 260 & HEB 280 & HEB 220 \\
\hline & 4 & HEB 240 & HEB 240 & HEB 200 \\
\hline & 5 & HEB 200 & HEB 220 & HEB 200 \\
\hline & 6 & HEB 160 & HEB 200 & HEB 160 \\
\hline
\end{tabular}

Table 3. Column sections for structure N3.

\begin{tabular}{|c|c|c|c|}
\hline STOREY & BAY & $\begin{array}{c}\text { CRITERION } \\
\text { A1 }\end{array}$ & EC8 \\
\hline 6 & 3 & SHS $27 \mathrm{X} .80$ & SHS 25X.8 \\
\hline \multirow{2}{*}{5} & 3 & SHS 38X 1.2 & SHS $25 X .8$ \\
\hline & 4 & SHS 38X 1.2 & SHS $25 X .8$ \\
\hline 4 & 4 & SHS 49X 1.4 & SHS 25X.8 \\
\hline \multirow{2}{*}{3} & 3 & SHS 57X 1.7 & SHS 27X.8 \\
\hline & 4 & SHS 57X 1.7 & SHS 27X.8 \\
\hline 2 & 3 & SHS 64X 1.9 & SHS $31 X 1$ \\
\hline \multirow{4}{*}{1} & 3 & SHS 66X 2 & SHS $31 X 1$ \\
\hline & 4 & SHS 66X 2 & SHS $31 X 1$ \\
\hline & 5 & SHS 23X .7 & SHS $21 X .7$ \\
\hline & 6 & SHS 23X .7 & SHS 19X .6 \\
\hline
\end{tabular}

mode (case "A0" and case "A1"), and to EC8 provisions have been reported in Table 1.

In the same way three different design solutions (case "A0", case "A1" and EC8) have been obtained for structural scheme N2. In this case, in order to satisfy the serviceability limit state an IPE270 has been adopted both for the structure designed according to the proposed procedure and for the structure designed according to EC8 [12] Table 2. 


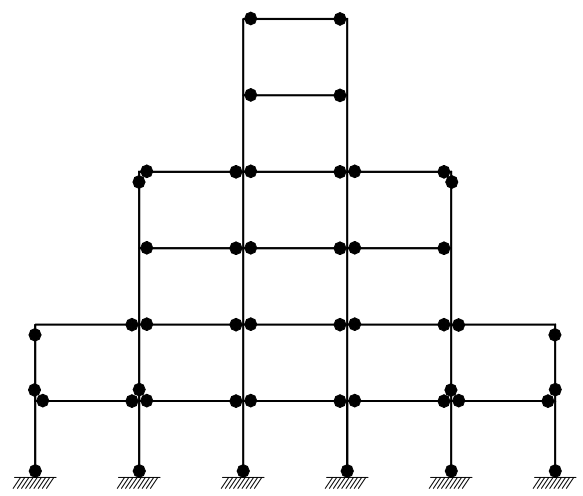

A0

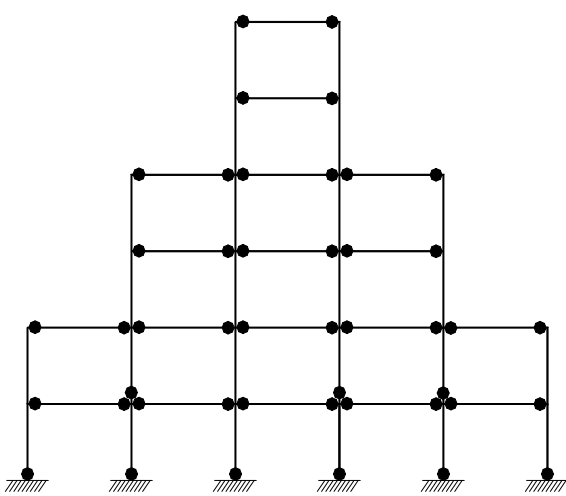

A1

Fig. (4). Collapse mechanism developed by the structures designed according to the proposed procedure.

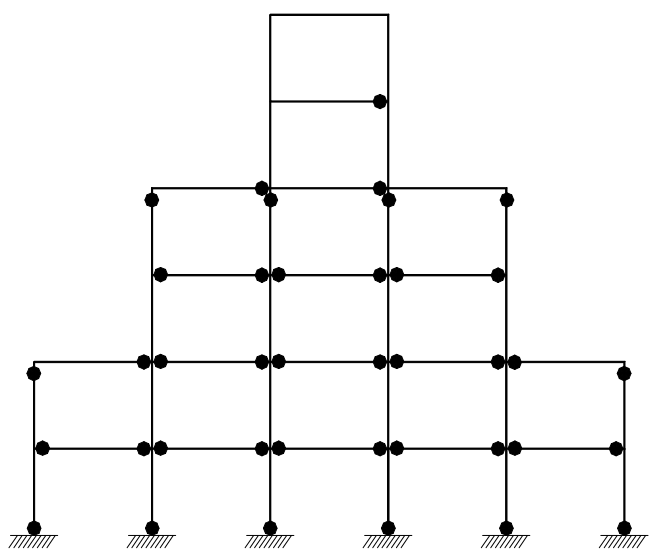

EC8

Fig. (5). Collapse mechanism developed by structure designed according to EC8 provisions.

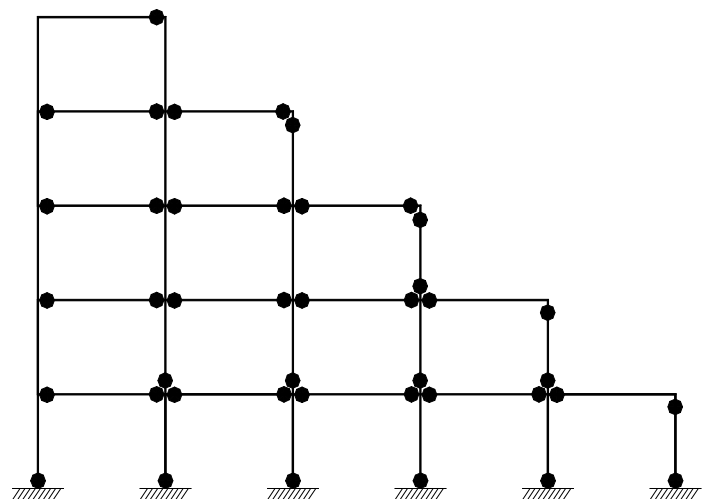

A0

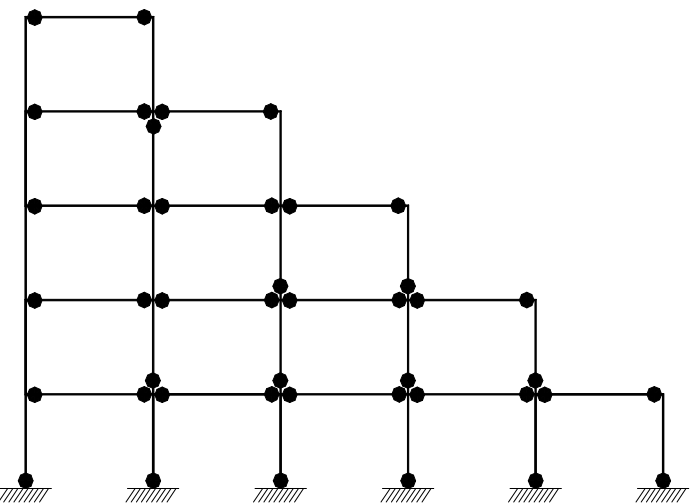

A1

Fig. (6). Collapse mechanism developed by the structures designed according to the proposed procedure.

With reference to structural scheme N3 an IPE270 is necessary for the structure designed according to the proposed procedure, and an IPE360 is necessary when EC8 provisions are used. In particular, for this structural scheme, only criterion "A1" has been considered, because the original criterion "A0" leads to the oversizing of the central columns of the first storey. This case shows that the alternative criterion "A1", summarized in Fig. (2), for the distribution of the sum of storey plastic moments is the more rational one in case of frames with set-backs. In Table 3 the obtained columns section for structural scheme N3 have been reported.

For all the analysed structures static non linear analyses have been performed by means of a spread plasticity approach using a fiber model [11]. In particular, the development of a collapse mechanism of global type has been confirmed for all the structures designed according to the proposed procedure Figs. $(\mathbf{4}, \mathbf{6}$ and $\mathbf{8})$. On the contrary, none of the structures designed according to EC8 provisions Figs. (5, 


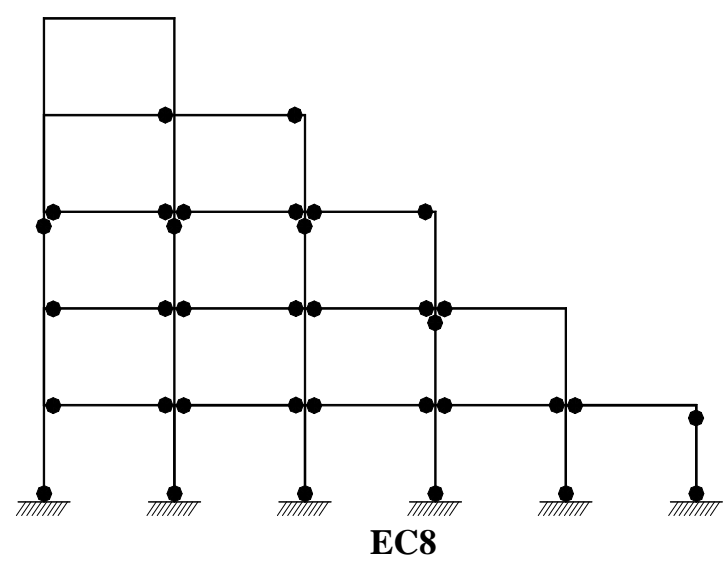

Fig. (7). Collapse mechanism developed by structure designed according to EC8 provisions
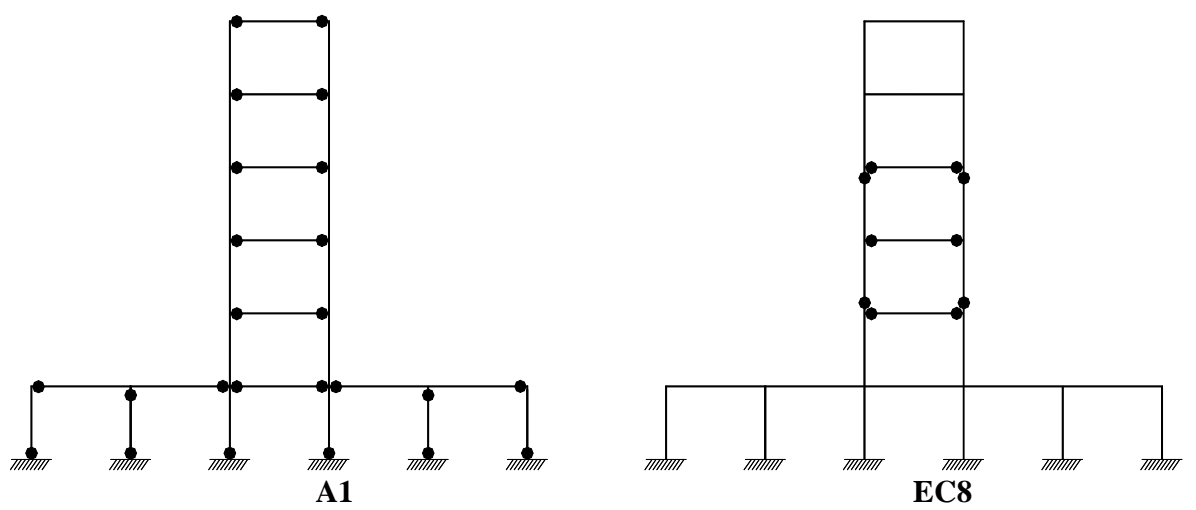

Fig. (8). Collapse mechanism developed by the structures designed according to the proposed procedure (left side) and the one designed according to EC8 provisions (right side).

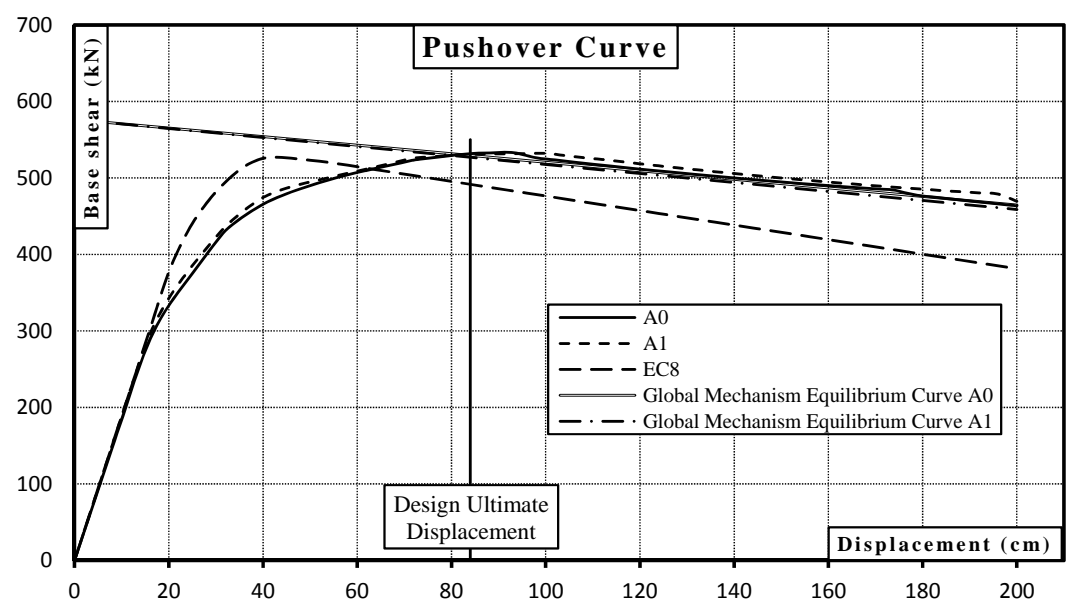

Fig. (9). Push-over curves for structural scheme N1.

7 and 8) exhibits a collapse mechanism of global type. In particular, a very poor dissipative mechanism, involving only two storeys, is obtained in case of structural scheme N3 when code design provisions are applied Fig. (8).

In addition, it can be noted that the softening branch of the push-over curves, i.e. the mechanism equilibrium curve, is very close to the theoretical one for all the analysed struc- tures designed according to the proposed procedure Figs. (9, $\mathbf{1 0}$ and 11). It is easy to verify from Table $\mathbf{1}$ and Table $\mathbf{2}$ that the application of the design procedure leads, for structural schemes $\mathrm{N} 1$ and $\mathrm{N} 2$, to an increase in structural weight of about $30 \%$ when compared with the one obtained by the application of EC8 provisions. This is the prize to be paid in order to obtain a more dissipative structure. 


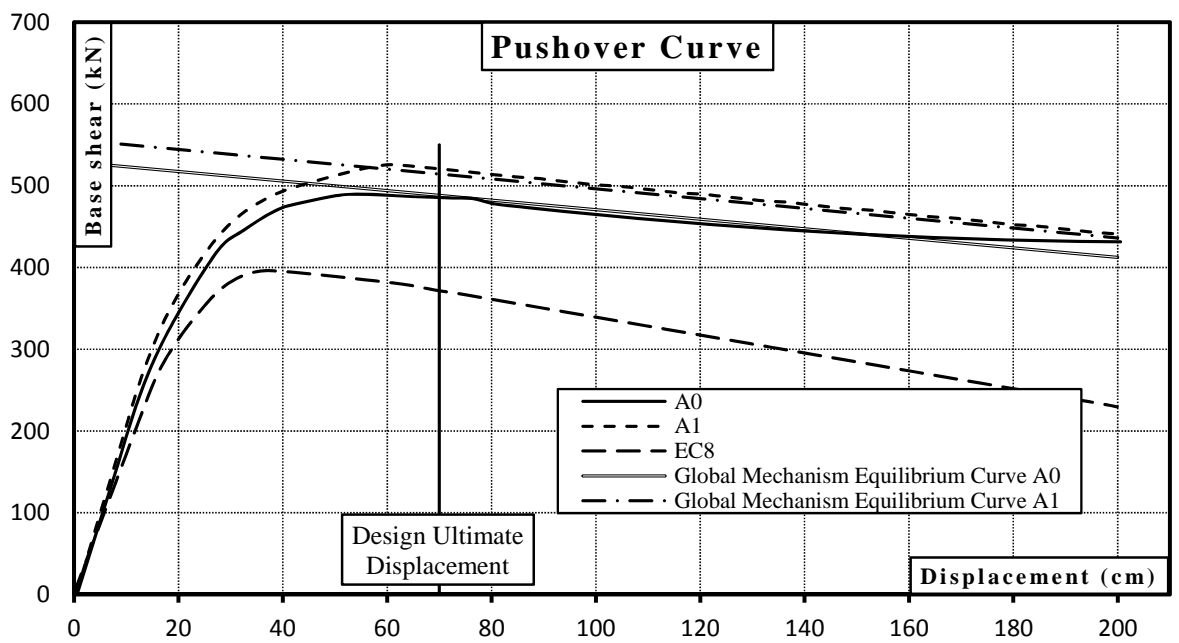

Fig. (10). Push-over curves for structural scheme N2.

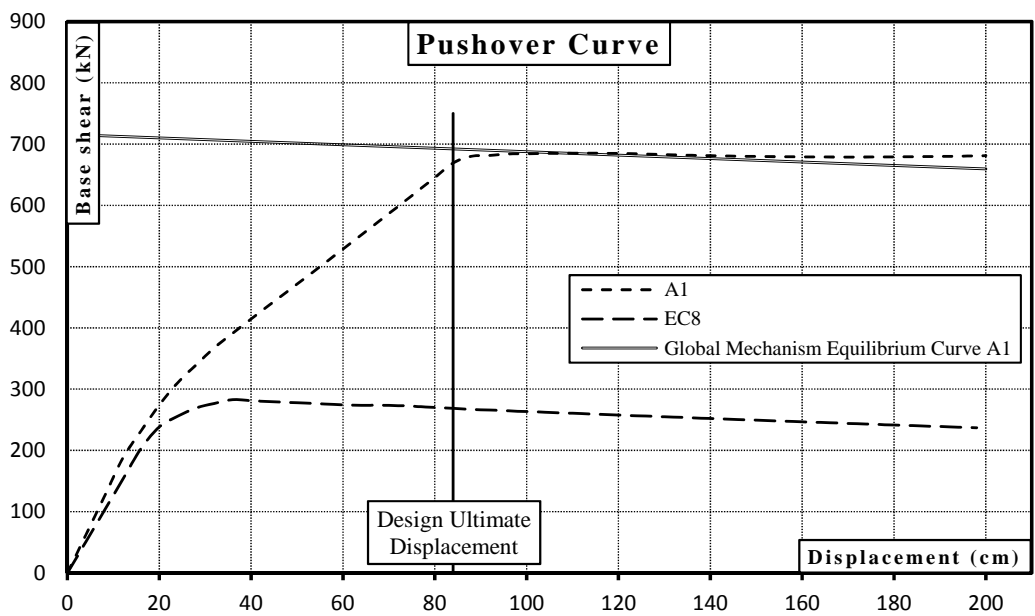

Fig. (11). Push-over curves for structural scheme N3.

However, it has to be underlined that the structural cost is only a part of the whole cost of the building. In particular, structural cost is commonly about $30 \%$ of whole building cost, so that it can be concluded that the plastic mechanism and energy dissipation capacity of frames with set-backs can be significantly improved by means of the proposed design procedure leading to a small increase, about $10 \%$, of the whole building cost.

\section{CONCLUSIONS}

In this paper, a sophisticated design methodology aimed at the failure mode control [1] has been extended to irregular moment resisting frames with set-backs. Such methodology provides, by means of the application of the upper bound theorem of plastic collapse, the sum of storey column plastic moments required to avoid undesired partial mechanisms. In particular, a specific procedure for distributing the required sum of column plastic moments among storey columns has been proposed for irregular MRFs with set-backs. In addition, several structures having different structural schemes have been analysed in order to point out the accuracy of the design methodology. By means of non-linear static pushover analyses, it has been shown that the collapse mechanism actually obtained is characterised by plastic hinge for- mation at both beam ends and at the base of first storey columns, i.e. a global mechanism is exhibited confirming the fulfillment of the design goal. On the contrary, the application of design rules provided by EC8 are not able to assure the complete exploitation of the structural plastic reserves, generally leading to partial collapse mechanisms.

\section{CONFLICT OF INTEREST}

The authors confirm that this article content has no conflicts of interest.

\section{ACKNOWLEDGEMENT}

Declared none.

\section{REFERENCES}

[1] F.M. Mazzolani, and V. Piluso, "Plastic design of seismic resistant steel frames", Earthquake Engineering and Structural Dynamics, vol. 26, pp. 167-191, 1997.

[2] A. Longo, R. Montuori, and V. Piluso, "Failure mode control of Xbraced frames under seismic actions", Journal of Earthquake Engineering, vol. 12, pp. 728-759, 2008.

[3] A. Longo, R. Montuori, and V. Piluso, "Plastic design of seismic resistant V-Braced frames", Journal of Earthquake Engineering, vol. 12, pp. 1246-1266, 2008. 
[4] A. Longo, R. Montuori, and V. Piluso, "Influence of Design Criteria on the Seismic Reliability of X-braced Frames", Journal of Earthquake Engineering, vol. 12, pp. 406-431, 2008.

[5] A. Longo, R. Montuori, and V. Piluso, "Seismic reliability of chevron braced frames with innovative concept of bracing members" Advanced Steel Construction, vol. 5 no. 4 , pp. 367-389, 2009.

[6] A. Longo, R. Montuori, and V. Piluso, "Seismic reliability of Vbraced frames: Influence of design methodologies", Earthquake Engineering and Structural Dynamics, vol. 38, pp. 1587-1608, 2009.

[7] M.T. Giugliano, A. Longo, R. Montuori, and V. Piluso, "Failure mode and drift control of MRF-CBF dual systems", The Open Construction and Building Technology Journal, vol. 4, pp. 121133,2010

[8] M.T. Giugliano, A. Longo, R. Montuori, and V. Piluso, "Plastic design of CB-frames with reduced section solution for bracing members", Journal of Constructional Steel Research, vol. 66, no. 5, pp. 611-621, 2010.

[9] M.T. Giugliano, A. Longo, R. Montuori, and V. Piluso, "Seismic reliability of traditional and innovative concentrically braced frames", Earthquake Engineering and Structural Dynamics, vol. 40, no. 1, pp. 1455-1474, 2011.

[10] A. Longo, R. Montuori, and V. Piluso, "Theory of plastic mechanism control of dissipative truss moment frames", Engineering Structures, vol. 37 , pp. 63-75, 2012.

[11] OpenSEES - Open System for Earthquake Engineering Simulation: Pacific Earthquake Engineering Research Centre, University of Berkeley, California, 1999.

[12] PrEN 1998-1. Eurocode 8: Design of Structures for Earthquake Resistance. Part 1: General Rules, Seismic Actions and Rules for Buildings CEN 2003.
[13] T. Paulay, Deterministic Design Procedure for Ductile Frames in Seismic Areas, ACI Publication SP-63, American Concrete Institute, Detroit, 1980, pp. 357-381.

[14] T. Paulay, "Seismic design of ductile moment resisting reinforced concrete frames, columns: evaluation of actions", Bulletin of New Zealand National Society of Earthquake Engeneering, vol. 10, pp. 85-94, 1977.

[15] T. Paulay, "Capacity design of earthquake resisting ductile multistorey reinforced concrete frames", Proc. 3rd Canad. Conf. on Earthquake Eng., Montreal, vol. 2, pp. 917-948, 1979.

[16] M. D. Engelhardt, and E. P. Popov, Behavior of long links in eccentrically braced frames, Report N. UCB/EERC-89/01, Earthquake Engineering Research Center, University of California, Berkeley, 1989.

[17] D.M. Nuove Norme Tecniche per le Costruzioni» e circolare esplicativa n. 617 del 02 febbraio 2009.(Italian Seismic Code) 14 January 2008.

[18] F. Iannone, M. Latour, V. Piluso, and G. Rizzano, "Experimental analysis of bolted steel beam-to-column connections: component identification", Journal of Earthquake Engineering, vol. 15, no. 2, pp. 214-244, 2011

[19] V. Piluso, G. Rizzano, and I. Tolone, "Seismic reliability assessment of a two-story steel-concrete composite frame designed according to Eurocode 8", Structural Safety, vol. 31, no. 5, pp. 383$395,2009$.

[20] L. Ascione, G. Mancusi, and S. Spadea, "Flexural behavior of concrete beams reinforced with GFRP bars", Strain, vol. 46, no. 5, pp. 460-469, 2010.

(c) Montuori et al.; Licensee Bentham Open.

This is an open access article licensed under the terms of the Creative Commons Attribution Non-Commercial License (http://creativecommons.org/licenses/by-nc/3.0/) which permits unrestricted, non-commercial use, distribution and reproduction in any medium, provided the work is properly cited. 